\title{
FAKTOR-FAKTOR YANG BERHUBUNGAN DENGAN KEJADIAN DERMATITIS PADA PEDAGANG IKAN DI PASAR TRADISIONAL KOTA KISARAN KABUPATEN ASAHAN
}

\section{RENI APRINAWATY SIRAIT ${ }^{1}$, ANITA OKTAVIANA SIREGAR ${ }^{2}$}

\author{
FAKULTAS KESEHATAN MASYARAKAT \\ INSTITUT KESEHATAN MEDISTRA LUBUK PAKAM \\ Jl. Sudirman No.38 Lubuk Pakam Kab. Deli Serdang, Sumatera Utara \\ Email: renisirait1982@gmail.com
}

DOI: $10.35451 / j k f . v 4 i 1.849$

\begin{abstract}
Occupational diseases are diseases that arise due to risk factors that come from work. Occupational diseases are one of the diseases that are often experienced by workers in their work, one of which is the work attitude factor which is influenced by inappropriate activities, not ergonomic for fish transportation and not using personal protective equipment so that there is a risk of dermatitis, which occurs in fish traders. This study aims to determine the factors associated with contact dermatitis due to the work of fish traders in traditional markets in the city of Asahan sub-district. This study is a quantitative study with a cross sectional design. The population in this study were all fish traders with a total of 52 workers. Samples were taken as 34 fisherman workers using purposive sampling technique. The instrument used is a questionnaire. The test used in this study used the chi-square test. From the results of statistical calculations, if the $p$ value (0.05) means that the hypothesis in this study is that there is a relationship between work attitude, length of work and tenure with the incidence of box dermatitis directly in fish. Based on the results of the research above, it is recommended for the promotion of health and safety, especially regarding the correct work attitude and the dangers of direct contact dermatitis that can be experienced. more intensively, such as holding collaborations between health offices to conduct counseling and for workers to use personal protective equipment such as rubber gloves as necessary.
\end{abstract}

Keywords: Dermatitis and fish Auction

\section{Pendahuluan}

Penyakit dampak kerja adalah penyakit yg ada menjadi dampak menurut gambaran faktor resiko yg dari menurut pekerjaan. Menurut World Health Organization (WHO) tahun 2015, per tahunnya tercatat 337 juta kecelakaan \& penyakit dampak kerja 
pada semua dunia. Setiap harinya masih ada 6.300 orang tewas dampak kecelakaan dampak kerja atau penyakit dampak kerja \& setiap tahunnya bisa mencapai 2,tiga juta kecelakaan \& penyakit dampak kerja (Andriani R, Hudayanah \& Hasmina, 2019).

Berdasarkan data Organisasi Buruh Internasional, lebih menurut 1,8 juta kematian dampak kerja terjadi setiapa tahunnya dikawasan Asia \& Pasifik, Bahkan 2 pertiga kematian dampak kerja pada global terjadi pada Asia. Di taraf global, lebih menurut 2,78 juta orang mati setiap tahun dampak kecelakaan atau penyakit dampak kerja. Selain itu, masih ada lebih kurang 374 juta cedera \& penyakit dampak kerja yg nir faal setiap tahunnya, yg poly menyebabkan absensix kerja (ILO, 2019). Penyakit Kulit Akibat Kerja. (PKAK) atau Occupational. Dermatoses (OD) adalah suatu kelainan kulit yg terjadi lantaran pekerjaan seseorang. Lingkungan industria akan mempengaruh insidensi menurut PKAK, Penyakit kulit yg acapkalikali ada merupakan dermatitis hubungan iritan (Safriyanti. 2017).

Data World Health Organization (WHO) tahun 2014, menyebutkan bahwa 50\%-90\% dari semua penyakit kulit akibat kontak dengan bahan kimia atau bekerja basah. Menurut studi epidemiologi di Indonesia yang telah dilakukan menunjukkan data bahwa 97\% dari 389 kasus adalah dermatitis kontak, yang terbagi menjadi $66,3 \%$ untuk kejadian dermatitis kontak iritan dan 33,7\% untuk kejadian dermatitis kontak alergi (Pradananingrum, dkk. 2018). Insiden dermatitis kontak akibat kerja diperkirakan sebanyak 0,5 sampai 0,7 kasus per 1.000 pekerja per tahun. Penyakit kulit diperkirakan menempati $9 \%$ sampai $34 \%$ dari penyakit yang berhubungan dengan pekerjaan. Dermatitis kontak akibat kerja biasanya terjadi di tangan dan angka insiden untuk dermatitis bervariasi antara $2 \%$ sampai $10 \%$. Diperkirakan sebanyak $5 \%$ sampai $7 \%$ penderita dermatitis akan berkembang menjadi kronik dan $2 \%$ sampai $4 \%$ di antaranya sulit untuk disembuhkan dengan pengobatan topikal (Safriyanti, 2017). Sedangkan berdasarkan data dinas kesehatan kasus penyakit kulit alergi berada pada urutan ke 9 dari 20 besar dengan jumlah kasus sebanyak 4731 kasus. Terdapat 2 (dua) faktor yang dapat mempengaruhi terjadinya dermatitis kontak yaitu faktor Internal dan faktor eksternal (Ramdan, I. M., Ilmiah, S. H. and F, A. R. 2018)

Dermatitis adalah peradangan kulit (epidemis dan dermis) sebagian respons terhadap pengaruh faktor eksogen, menyebabkan kelainan klinis berupa efloresensi polimorfik (eritema, edema, vesikel, skuama, likenifikasi) dan keluhan gatal . tanda poliformik tidak selalu terjadi bersamaan, bahkan mungin hanya satu jenis misalnya hanya berupa papula (oligomorfik). Dermatitis cenderung residif dan menjadi kronis (Sri Adi Sularsito dan Retno W. Soebaryo, 2015).

Faktor internal meliputi faktor genetik, jenis kelamin, umur, etnis, lokasi kulit, dan riwayat atopi. Faktor eksternal meliputi sifat-sifat bahan kimia iritan $(\mathrm{pH}$, keadaan fisik, konsentrasi, 3 ukuran molekul, jumlah, polarisasi, ionisasi, bahan pembawa dan kelarutan), karakteristik paparan (jumlah, konsentrasi, durasi, jenis kontak, paparan simultan terhadap iritan lainnya, dan interval setelah paparan sebelumnya), faktor lingkungan (suhu, dan kelembapan), faktor mekanik 2 (tekanan, gesekan, atau abrasi), dan radiasi ultraviolet (UV) (Sularsito dan Djuanda, 2009). Penyebab dermatitis kontak alergi adalah alergen, paling sering berupa 
bahan kimia dengan berat kurang dari 500-1000, yang juga disebut bahan kimia sederhana. (Rahma, G. A., Setyaningsih, Y. and Jayanti, S. 2017). Berdasarkan penelitian di United Kingdom (UK), ditemukan bahwa agen dengan jumlah tertinggi untuk kasus dermatitis kontak alergi adalah karet (23,4\% kasus alergi dilaporkan oleh ahli kulit), nikel $(18,2 \%)$, epoxies dan resin lainnya $(15,6 \%)$, amina aromatik $(8,6 \%)$, krom dan kromat $(8,1 \%)$, pewangi dan kosmetik $(8,0 \%)$, dan pengawet $(7,3 \%)$. Sedangkan sabun $(22,0 \%$ kasus), pekerjaan basah $(19,8 \%)$, produk minyak bumi $(8,7 \%)$, pelarut/solvent $(8,0 \%)$, dan cuttingoil dan pendingin $(7,8 \%)$ adalah agen yang paling sering ditemukan dalam kasus dermatitis iritan. (Behroozy, A. And Keegel, T. G.,2014).

Berbagai jenis ikan dijual oleh para pedagang ikan segar dan aktifitas yang dilakukan oleh pedagang ikan segar diantaranya yaitu membersihkan ikan, memotong ikan, menyimpan (mengawetkan) ikan di dalam kotak penyimpanan serta membersihkan tempat berjualan ikan (Arie retnoningsih, 2017). Pengawetan ikan laut dilakukan 5 dengan menggunakan es dan garam di dalam wadah penyimpanan. Pada aktifitas tersebut pedagang ikan segar terus-menerus berkontak dengan air, baik air dari rendaman ikan maupun air yang digunakan saat melakukan aktifitas tersebut (Cahyawati, 2011).

Terjadinya dermatitis akibat kerja ini bukan hanya dipengaruhi oleh faktor kontak dengan bahan kimia iritan sajakan tetapi juga dipengaruhi oleh faktor-faktor lainnya. Masa kerja dan lama kerja penting diketahui untuk melihat lamanya seseorang terpajan dengan faktor risiko yang dapat mempengaruhi kesehatan seseorang (Setiawan, dkk. 2016).

Pasar Tradisional sebagai pasar rakyat merupakan salah satu indikator paling nyata dari kegiatan ekonomi masyarakat di suatu wilayah, termasuka disumaterautara. Tidak tersedianya sabun untuk mencuci tangan dan kaki serta kurang tercukupinya kebutuhan air bersih juga menjadi pemicu buruknya kebersihan diri pedagang ikan disaat dan setelah2 bekerja Oleh karena itu peneliti ingin mengetahui faktor-faktor yang berhubungan dengan kejadian dermatitis kontak iritan pada pedagang ikan di pasar tradisional Kota Kisaran.

\section{METODE PENELITIAN}

Jenis penelitian yang digunakan pada penelitian ini adalah bersifat survey analitik observasional dengan menggunakan crosssectional. Populasi penelitian sebanyak 52 pedagang ikan di pasar tradisional kota kisaran dan Sampel yang digunakan sebanyak 34 pedagang ikan dengan menggunakan tehnik pengambilan sampel Kuota sampling. Tempat penjualan ikan atau yang sering disebut dengan TPI merupakan suatu wadah tempat berlangsungnya penjualan hasil-hasil penangkapan ikan dari laut untuk menyalurkan hasil tangkapan nelayan kepada pembeli dengan sistem lelang. Tempat Pelelangan Ikan (TPI) yang didirikan pada tahun 1976 oleh pemerintah kabupaten yang berlokasi di kota kisaran timur yang berlokasi kisaran timur pada tahun 1986 tempat penjual ikan kota kisaran timur.

Tempat penjualan ikan dipasar tardisional kota kisaran.Tempat pelelangan ikan memiliki luas bangunan $450 \mathrm{~m} 2$ dan luas areal perikanan sebesar 3,70 $\mathrm{Ha}$ yang terletak di kabupaten asahan kota 
kisaran timur. Setelah melakukan data terhadap 34 responden di tempat penjualan ikan (TPI) di kabupaten Asahan kota kisaran timur pada priode waktu 10 mei hingga 17 mei 2021 maka di dapatkan data yang berkaitan dengan penelitian ini., Data karateristik responden meliputi data Jenis Kelamin, Umur, Massa Kerja Pemakaian APD Hygiene Personal dan massa kerja.

\section{HASIL}

Hasil analisis data diperoleh chisquare sebesar 24 deengan probabilitas $0,000<0,05$ yanga artinya bahawa ada hubungan yang signifikan antara massa kerja dengan kejadian dermatitis pada pedagang ikan di kota kisaran. Massa kerja seseorang menentukan tingkat pengalama seseorang dalam menguasai pekerjaanya.dimana sebagian besar $\quad(75 \%)$ pedagang penderita dermatitis semuanya memiliki massa kerja 2 tahun atau kurang ,sebaliknya yang tidak menderita dermatitis semuanya memiliki masa lebih dari dua tahun sebesar (25\%). Hal ini dimungkinkan bahwa para pekerja yang telah bekerja lebih dari dua tahun telah memiliki resistensi terhadap bahan iritan maupun alergen, sehingga penderita dermatitis kontak pada kelompok ini cenderung sedikit ditemukan. Pekerja dengan lama kerja kurang atau sama dengan 2 tahun dapat menjadi salah satu faktor yang mengindikasikan bahwa pekerja tersebut belum memiliki pengalaman yang cukup dalam melakukan pekerjaanya.

Hal ini sesuai dengan pendapat yang disampaikan oleh Fatma Lestari dan Hari Suryo Utomo (2007), bahwa pekerja dengan pengalaman akan lebih berhati-hati sehingga kemungkinan terpajan bahan iritan maupun alergen lebih sedikit. Berlaku sebaliknya bahwa pada pekerja dengan lama bekerja lebih dari 2 tahun dapat dimungkinkan telah memiliki resistensi terhadap bahan iritan maupun alergen. Untuk itu pekerjaan dengan lama bekerja lebih dari 2 tahun lebih sedikit yang mengalami dermatitis kontak (Fatma Lestari dan Hari Suryo Utomo, 2007).

Hal ini sejalan juga dengan hasil penelitian Nuriyanti, 2019. bahwa pekerja yang tidak menggunakan Alat pelindung diri dengan masa kerja melebihi 2 tahun lebih banyak mengalami dermatitis kontak iritandibandingkan dengan yang menggunakan alat pelindung diri. ( Nuryanti, 2019)

Tabel 1. Distribusi Frekuensi Jenis Kelamin, Umur, Massa Kerja Pemakaian APD Hygiene Personal dan massa kerja responden pedagang penjualan ikan kisaran.

\section{No Karateristik Frekuensi}

(\%)

\begin{tabular}{|c|c|c|c|}
\hline \multirow[t]{3}{*}{1.} & \multicolumn{3}{|l|}{ Jenis Kelami } \\
\hline & Laki-Laki & 34 & 100 \\
\hline & Total & 34 & 100 \\
\hline \multirow[t]{5}{*}{2.} & Umur & & \\
\hline & $\leq 40$ tahun & 39 & 35 \\
\hline & $>40$ tahun & 16 & 47 \\
\hline & $\leq 10$ tahun & 6 & 18 \\
\hline & Total & 34 & 100 \\
\hline \multirow[t]{5}{*}{3.} & $\begin{array}{l}\text { Massa kerja } \\
\text { pemakain } \\
\text { APD }\end{array}$ & & \\
\hline & 1 jam & 15 & 44 \\
\hline & 2 jam & 15 & 44 \\
\hline & 3 jam & 4 & 12 \\
\hline & Total & 34 & 100 \\
\hline \multirow[t]{3}{*}{4.} & $\begin{array}{c}\text { Massa Kerja } \\
<2 \text { Tahun }\end{array}$ & 15 & 75 \\
\hline & $\leq 2$ Tahun & 2 & 25 \\
\hline & Total & 34 & 100 \\
\hline
\end{tabular}


Berdasarkan Tabel 3.1 di atas menunjukkan bahwa distribusi frekuensi karaktersitik Jenis Kelamin diketahui dari $34(100,0 \%)$ responden terdapat bahwa 34 orang $(100,0 \%)$ berjenis kelamin laki-laki, Distribusi frekuensi karateristik Umur Responden pekerja bagian penjualan ikan di pasar tradisional dari $\leq 40$ tahun $(100,0 \%)$ responden diketahui bahwa mayoritas responden dengan umur, >40 tahun berjumlah 16 orang $(47,1 \%)$, Distribusi frekuensi karateristik pekerja penjualan ikan di pasar tradisional ikan berdasarkan massa kerja menggunakan APD dari $34(100,0 \%)$ responden diketahui mayoritas pekerja memiliki lama kerja selama 1 jam berjumlah 15 Orang $(44,1 \%)$ dan 2 jam berjumlah 15 Orang $(44,1 \%)$, Distribusi frekuensi karateristik pekerja bagian pengangkutan hasil tangkap ikan berdasarkan massa kerja dari $34(100,0 \%)$ responden diketahui bahwa mayoritas responden bekerja $>2$ tahun dengan jumlah 15 Orang (75 \%).

Tabel 2 Keterkaitan Antara Faktor alat Pelindung Diri Dengan Kejadian Dermatitis Pada pedagang ikan di pasar tradisional kota kisaran.

\begin{tabular}{lll}
\hline $\begin{array}{l}\text { Pemakaian } \\
\text { APD }\end{array}$ & $\begin{array}{l}\text { Frekuensi } \\
(\mathbf{N})\end{array}$ & $\begin{array}{l}\text { Persentase } \\
(\mathbf{\%})\end{array}$ \\
\hline Baik & 16 & 47,1 \\
$\begin{array}{l}\text { Kurang } \\
\text { Baik }\end{array}$ & 18 & 52,9 \\
\hline Total & $\mathbf{3 4}$ & $\mathbf{1 0 0 , 0}$
\end{tabular}

Berdasarkan Tabel 3.2 di atas menunjukkan bahwa distribusi frekuensi sikap kerja diketahui dari 34 $(100,0 \%)$ responden terdapat bahwa mayoritas responden memiliki sikap kerja yang kurang baik berjumlah 18 orang (52,9\%).

Tabel 3 Keterkaitan Antara Faktor Riwayat Pekerjaan Dengan Kejadian Dermatitis Pada pedagang ikan di pasar tradisional kota kisaran.

\begin{tabular}{|c|c|c|}
\hline $\begin{array}{l}\text { Riwayat } \\
\text { Pekerjaan }\end{array}$ & $\begin{array}{l}\text { Frekuensi } \\
\text { (N) }\end{array}$ & $\begin{array}{l}\text { Persen } \\
(\%)\end{array}$ \\
\hline Ada & 13 & 70 \\
\hline Tidal & 7 & 30 \\
\hline Total & 34 & 100,0 \\
\hline \multirow{2}{*}{\multicolumn{3}{|c|}{$\begin{array}{l}\text { Berdasarkan Tabel } 3.3 \text { di atas } \\
\text { menunjukkan bahwa hasil uji chi-squer } \\
\text { i p } 0,027<0,05 \text {,yang berarti ada } \\
\text { hubungan yang signifikan antara } \\
\text { riwayat pekerjaan dengan kejadian } \\
\text { dermatitis. } \\
\text { Tabel } 4 \text { Keterkaitan Antara Faktor } \\
\text { HygienePersonal Dengan Kejadian } \\
\text { Dermatitis Pada Pedagang Ikan Di } \\
\text { Pasar Tradisonal Kota Kisaran. }\end{array}$}} \\
\hline & & \\
\hline $\begin{array}{l}\text { Hygiene } \\
\text { Personal }\end{array}$ & $\begin{array}{l}\text { Frekuensi } \\
\text { (N) }\end{array}$ & $\begin{array}{c}\text { Persentase } \\
(\%)\end{array}$ \\
\hline Baik & 7 & 30 \\
\hline Buruk & 13 & 70 \\
\hline Total & & 100,0 \\
\hline
\end{tabular}

\section{PEMbahasan}

Hasil analisis data diperoleh chisquaresebesar 24 deengan probabilitas $0,000<0,05$ yanga artinya bahawa ada hubungan yang signifikan antara massa kerja dengan kejadian dermatitis pada pedagang ikan di kota kisaran.

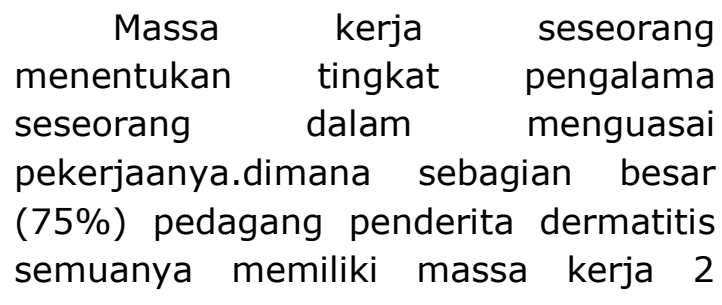


tahun atau kurang ,sebaliknya yang tidak menderita dermatitis semuanya memiliki masa lebih dari dua tahun sebesar (25\%). Hal ini dimungkinkan bahwa para pekerja yang telah bekerja lebih dari dua tahun telah memiliki resistensi terhadap bahan iritan maupun alergen, sehingga penderita dermatitis kontak pada kelompok ini cenderung sedikit ditemukan. Pekerja dengan lama kerja kurang atau sama dengan 2 tahun dapat menjadi salah satu faktor yang mengindikasikan bahwa pekerja tersebut belum memiliki pengalaman yang cukup dalam melakukan pekerjaanya.

Hal ini sesuai dengan pendapat yang disampaikan oleh Fatma Lestari dan Hari Suryo Utomo (2007), bahwa pekerja dengan pengalaman akan lebih berhati-hati sehingga kemungkinan terpajan bahan iritan maupun alergen lebih sedikit. Berlaku sebaliknya baha pada pekerja dengan lama bekerja lebih dari 2 tahun dapat dimungkinkan telah memiliki resistensi terhadap bahan iritan maupun alergen. Untuk itu pekerjaan dengan lama bekerja lebih dari 2 tahun lebih sedikit yang mengalami dermatitis kontak (Fatma Lestari dan Hari Suryo Utomo, 2007).

Hasil analisis data diperoleh chisquare sebesar 10,417 dengan probabilitas 0,001 $<0,05$ yang artinya bahwa ada hubungan yang signifikan antara pemakaian alat pelindung diri dengan kejadian dermatitis pada nelayan yang bekerja di tempat penjualan ikan. salah satu faktor penyebabnya adalah tempat kerja sehingga termasuk dalam jenis dermatitis akibat kerja, jadi pemakaian alat pelindung diri merupakan salah satu upaya yang dapat dilakukan untuk meminimalkan resiko. Pemakaian alat pelindung diri, maka akan menghindarkan seseorang kontak langsung dengan agen-agen fisik, kimia maupun biologi (Kementerian Kesehatan Republik Indonesia, 2015). Hasil penelitian menunjukkan bahwa sebesar 17 dari 24 (85\%) nelayan penderita dermatitis tidak memakai alat pelindung diri saat melakukan pekerjaannya. Hal ini sejalan dengan pendapat yang disampaikan oleh Fatma Lestari dan Hari Suryo Utomo (2007), bahwa jika tenaga kerja atau pekerja dalam bekerja tidak memakai alat pelindung diri maka kulit menjadi tidak terlindungi dan kulit menjadi lebih mudah terpapar oleh bahan iritan maupun alergen.

Hasil analisis data diperoleh chi-square sebesar 4,912 dengan probabilitas

$0,027<0,05$ yang artinya bahwa ada hubungan yang signifikan antara riwayat pekerjaan dengan kejadian dermatitis pada nelayan yang bekerja di tempat.

Penjualan ikan di pasar tradisional, Riwayat pekerjaan merupakan salah satu faktor yang dapat dipertimbangkan sebagai penyebab penyakit dermatitis. Hal ini dimungkinkan penyakit dermatitis diderita bukan akibat pekerjaan yang dijalaninya sekarang, tetapi akibat pekerjaan sebelumnya. Sebagian besar responden di TPI yang terdeteksi menderita dermatitis memiliki riwayat pekerjaan sebelumnya di bidang pertanian, salon, percetakan, pom bensin, di pasar maupun pertukangan. Sebanyak 13 dari 19 (90\%), respomden memiliki riwayat pekerjaan yang memberikan peluang terjangkitnya penyakit dermatitis. Misalnya akibat paparan benda asing, bahan kimia, biologi atau lingkungan tempat bekerja terdahulu. Seperti pada pekerja yang biasa terpajan dengan sensitizer, seperti kromat pada industri bangunan atau pewarna, pada pabrik 
pengolahan kulit, mempunyai insiden yang lebih tinggi (Lau, M. Y. Z. etal. (2011).

Hasil analisis data diperoleh chisquare sebesar 4,912 dengan probabilitas $0,027<0,05$ yang artinya bahwa ada hubungan yang signifikan antara hygiene personal dengan kejadian dermatitis pada nelayan yang bekerja di tempat Penjualan ikan kota kisaran. Di tempat pelelangan ikan kondisi kebersihan lingkungannya kurang sehat dan nyaman. Hal ini dimungkinkan akibat segala kegiatan di tempat pelelangan ikan ternyata menimbulkan banyak sekali sampah dari sisa-sisa ikan dan banyak air yang tergenang di lantai karena tersumbatnya aliran air, hal ini akan memberikan dampak negatif pada tempat kerja yaitu pencemaran lingkungan kerja (Bustami Mahyuddin, 2007). Akibatnya nelayan yang bekerja di tempat pelelangan ikan akan mendapatkan resiko terkena penyakit menular dan tidak menular. Beberapa contoh penyakit yang dapat timbul di tempat pelelangan ikan yaitu Dermatitis, Desentri, dan Thypus (Joko Suyono, 1995: 195). Hasil penelitian menunjukkan bahwa 13 dari 19 (65\%) responden menderita dermatitis dengan hygiene personal yang buruk.

\section{KESIMPULAN}

Berdasarkan hasil penelitian tentang fakor-faktor yang berhubungan dengan kejadian dermatitis pada pedagang ikan di pasar tradisional kota kisaran yang bekerja di tempat penjualan ikan (TPI) dapat disimpulkan bahwa:

1. Ada hubungan antara masa kerja dengan kejadian dermatitis pada pedagang ikan di pasar tradisional kota kisaran tahun 2021.

2. Ada hubungan antara pemakaian APD dengan kejadian dermatitis pada pedagang ikan di pasar tradisional kota kisaran tahun 2021.

3. Ada hubungan antara riwayat pekerjaan dengan kejadian dermatitis pada pedagang ikan di pasar tradisional kota kisaran tahun 2021.

4. Ada hubungan antara dengan hygiene personal dermatitis pedagang ikan di pasar tradisional kota kisaran tahun 2021.

5. Ada hubungan antara riwayat penyakit kulit dengan kejadian dermatitis pada pedagang ikan di pasar tradisional kota kisaran tahun 2021.

6. Ada hubungan antara riwayat alergi dengan kejadian dermatitis pada pedagang ikan di pasar tradisional kota kisaran tahun 2021.

\section{DAFTAR PUSTAKA}

Arie Retnoningsih, 2017. Analisis Faktor-Faktor Kejadian Dermatitis Kontak Pada Nelayan, Semarang: Fakultas Kesehatan Masyarakat Uniferitas Muhamadiyah Semarang.

Andriani R, Hudayanah \& Hasmina, (2019) Rendahnya Tingkat Pelayanan Kesehatan Dilingkungan Nelayan Jurnal Kesehatan Masyarakat (eJournal) Bogor.

Behroozy, A. And Keegel, T. G. (2014) 'Wet-workexposure: A main risk factor for occupation alhand dermatitis', Safety and Health at Work. Elsevier Ltd, 5(4), pp. 175180.

Cahyawati, I. and Budiono, I. (2011) 'Faktor yang Berhubungan dengan Kejadian Dermatitis pada Nelayan', KEMAS: Jurnal Kesehatan Masyarakat, 6(2), pp. 
134-141.

doi: 10.15294/kemas.v6i2.1766.

ILO (2019), Keselamatan dan kesehatan kerja, keselamatan dan kesehatan sarana untuk produktivitas. Bahasa Ind ed, Jakarta

Kementerian Kesehatan Republik Indonesia. Seri Pedoman Tatalaksana Penyakit Akibat Kerja bagi Petugas Kesehatan. Jakarta: Kementerian Kesehatan Republik Indonesia; 2015.

Lau, M. Y. Z. etal. (2011) 'A Reviewof the Impactof Occupational Contact Dermatitis on Qualityof Life', Journal of Allergy, 2011, pp. $1-12$. doi: $10.1155 / 2011 / 964509$.

Lestari F, Utomo HS. Faktor-Faktor yang Berhubungan dengan Dermatitis Kontak pada Pekerja di PT Inti PanjtaPress Industri. Makara Kesehatan. 2007;11(2):61-8.

Nuryanti, (2019). Hubungan Aktifitas Fisik dengan kejadian dermatitis pada nelayan di Desa Pantai Cermin Kanan Kabupaten serdang Bedagai. Skripsi Kesehatan Masyarakat.

Pradananingrum, S., Lestantyo, D. and Jayanti, S. (2018) 'Hubungan Personal Hygiene, Lama Kontak, Dan Masa Kerja Dengan Gejala Dermatitis Kontak Iritan Pada Pengrajin Tahu Mrican Semarang', Jurnal Kesehatan Masyarakat (eJournal), 6(4), pp. 378-386.

Rahma, G. A., Setyaningsih, Y. and Jayanti, S. (2017) 'Analisis Hubungan Faktor Eksogen Dan Endogen Terhadap Kejadian Dermatitis Akibat Kerja Pada Pekerja Penyamakan Kulit Pt. Adi Satria Abadi Piyungan, Bantul', Jurnal Kesehatan
Masyarakat (e-Journal), 5(5), pp. 173-183.

Ramdan, I. M., Ilmiah, S. H. and F, A. $\mathrm{R}$.

occupationalIrritanContact

(2018)

Dermatitis among Shipyard Workers in Samarinda, Indonesia', Jurnal Kesehatan Masyarakat, 14(2), pp. 239246. 10.15294/kemas.v14i2.13417.

Safriyanti, 2017.Hubungan Personal Hygiene, Lama Kontak dan Riwayat Penyakit Kulit dengan Kejadian Dermatitis Kontak pada Petani Rumput Laut di Desa Akuni Kecamatan Tinanggae Kabupaten Konawe Selatan Tahun 2017.

Setiawan, dkk. 2016. Higiene Kesehatan Kerja (Hiperkes).

Sularsito, Djuanda (2009) Ilmu Penyakit Kulit dan kelamin, Dermatitis. Jakarta: Fakultas Kedokteran Universitas Indonesia

Sri Adi Sularsito dan Retno W. Soebaryo, 2015. Ilmu penyakit kulit dan kelamin, Jakarta: FK UI.

WHO. 2014. Dasar-Dasar Keselamatan dan Kesehatan Kerja. 